\title{
GENERALIZED MODELS OF REPAIRABLE SYSTEMS A SURVEY VIA STOCHASTIC PROCESSES FORMALISM
}

\author{
R. GUO, H. ASCHER AND E. LOVE \\ University of Cape Town, South Africa, H.E.Ascher \& Associates, United States of \\ America, and Simon Fraser University, Canada
}

\begin{abstract}
In this article, we survey the developments in the generalised models of repairable systems reliability during 1990s, particularly the last five years. In this field, we notice the sharp fundamental problem that voluminous complex models were developed but there is an absence of sufficient data of interest for justifying the success in tackling the real engineering problems. Instead of following the myth of using simple models to face the complex reality, we select and review some practical models, particularly the stochastic processes behind them. The Models in three quick growth areas: age models, condition monitoring technique related models, say, proportional intensity and their extensions, and shock and wearing models, including the delay-time models are reviewed. With the belief that only those stochastic processes reflecting the instinct nature of the actual physical processes of repairable systems, without excessive assumptions, may have a better chance to meet the demands of engineers and managers.
\end{abstract}

\section{INTRODUCTION}

General speaking, a reasonable reliability model might be understood as a formalism which is flexible enough to capture up approximately the dynamic changes of a physical system during its functioning life time. It is worth to mention the comprehensive volume edited by Ushakov and Harrison [88], which reflected the huge research efforts before 1990s.

Tracing the recent years' developments on repairable system modelling, there are two tendencies worthy of mention: first, it should be noticed that it is in general to engage the mathematical developments by imposing lifetime distributions or the transition probability matrix into the related models but rarely to consider the engineering information underlying physical mechanism behind those models and therefore caused great difficulties in applying 
such models ; secondly, it should be noticed that "pure" statistical or stochastic analysis (discussing issues of estimation and hypothesis testing, particularly on repair improvement effect) on repairable systems are very rare in the reliability engineering literature, just as Scarf [75] repeated Ascher and Feingold's [1] point twenty-year ago. At present, too little attention is paid to data collection and considering usefulness of models for solving problems through model fitting and validation. Too much attention is paid to the invention of new models, with little thought, it seems, as to their applicability. It is noticeable that many varieties of models appeared in maintenance policy making research, just like mathematical model competition. It is not deniable that a certain class of maintenance models and the related optimisation process also generate some estimates. In other words, there are two kinds of estimates: the system operating and maintenance performance based estimates and the assumed modelling based estimates. The former reflects the engineering reality and the estimates are statistical but the latter only the mathematical modelling ideology. However it is an undeniable fact that a substantial efforts has been made in the aspect of maintenance optimisation, for example, Dekker [23] and [24], El-Yaniv and Karp [26], Garren and Richard [33], Haurie [45], Pintelon, Van Puyvelde and Gelders [72], Righter [74], Sheu [76], [77] and [78], Sheu and Jhang [79], Singh and Singh [82], Matsushima, Kaio and Osaki [86], and Van der Duyn Schouten and Vanneste [89], Gouweleeuwn [38] etc. Now we urgently need practical models rather than ideal mathematical models and related optimisations, because the later, just as Van Noortwijs, Cooke and Kok [68] pointed out, "in spite of voluminous theoretical researches, very few applications of maintenance optimisation were found".

We noticed that two important featured review papers on maintenance modelling appeared in last five years period, Pham and Wang [71] and Scarf [75]. Scarf [75] promoted the engineering supported simple models and identified the three quick growth areas. However, he tended to avoid the complex models, particular virtual age models, while Pham and Wang [71] collected and reviewed more than forty models but ignored the most important three quick growth areas, particularly condition monitoring technique based model, e.g. proportional intensity model developments.

About imperfect maintenance modelling and optimisations, Pham and Wang [71] reviewed more than 40 models appeared in the literature before 1995 for repairable systems (maintenance) and classified them into eight categories: 


\begin{tabular}{|c|c|c|}
\hline $\begin{array}{l}\text { Pham-Wang's } \\
\text { Classification }\end{array}$ & Model initiated by & Features \\
\hline$(p, q)$-rule & Nakagawa (1979) & $\begin{array}{l}\text { Homogeneous hybrid } \\
\text { model }\end{array}$ \\
\hline$(p(t), q(t))$-rule & Block et al. (1985) & $\begin{array}{l}\text { Non-homogeneous hybrid } \\
\text { model }\end{array}$ \\
\hline $\begin{array}{l}\text { Improvement factor } \\
\text { method }\end{array}$ & Malik (1979) & Improvement factor model \\
\hline Virtual age model & Kijima et al. (1989) & $\begin{array}{l}\text { Virtual age as the key state } \\
\text { parameter }\end{array}$ \\
\hline Shock model & Esary et al. (1973) & $\begin{array}{l}\text { Accumulated shock } \\
\text { damages }\end{array}$ \\
\hline$(\alpha, \beta)$-rule & Wang et al. (1996) & Fractional life time model \\
\hline Multiple $(p, q)$-rule & Shaked et al. (1986) & Multivariate hybrid model \\
\hline Others & Nakagawa (1979) & \\
\hline
\end{tabular}

Table 1: Pham-Wang's model summary

The term hybrid here means a probabilistic mixture of same-as-new and same-as-old as Barlow and Proschan specified and homogeneous is referred to as the probability "weight" is not time varying. We use terms same-as-new and same-as-old replace popular but misleading terms good-as-new and bad-as-old (which was first used by Ascher as the alternative of minimal repair initiated by Barlow and Hunter [8]) respectively as intuitive images of renewal and Non-homogeneous Poisson Processes (NHPP). For example, if the underlying process of a repairable system is a Weibull renewal with shape parameter less than one then the hazard function is monotone decreasing and tends to zero if the operating time tends to infinity long. A renewal type repair will make the system's hazard jumping into infinity large. In such a case, the system is not really good after renewal. Similarly, bad-as-old is equally misleading for an NHPP of decreasing ROCOF as an improving system. Good-as-new and bad-as-old only apply to repair-improving systems but not to those improved in terms of non-stopping operation. 
Without any doubts, those developments have enhanced the repairable system modelling literature greatly but the endless growth of mathematical models may partly reflect the demands of industry and business. However, the models reviewed by Pham and Wang [71] were short of insight into of the instinct physical nature of repairable systems and have a taste of mathematical model obsessions. This may be the reason why they excluded in their review paper the developments in conditional monitoring models, say, proportional intensities model.

Scarf [75] passionately promoted the engineering information based models and identified three "special growth areas": models related to condition monitoring technique, complex multi-component system models and delay-time distribution models. However, he ignored the quick growth area of virtual age models, maybe he believed that virtual age models are not “simple" enough.

What is a simple model? "Simple" model should not be referred as to those in the literature appeared earlier or simple in mathematical form. For example, renewal processes (same-asnew) and non-homogeneous Poisson processes (same-as-old) seem simple in mathematical definitions, but in practice, the assumptions are rarely satisfied, just as Guo and Love [42] reported that both same-as-new and same-as-old are very strong assumptions. Twisted with simplicity seeking, misconceptions and malpractice in reliability engineering literature are persistent symptoms, just as exposed systematically in Ascher and Feingold [1], Ascher [2] and [5], Ascher and Kobbacy [3], Ascher and Hansen [4] and [6]. Therefore, what is a simple model is a very debatable issue. We would argue that the complexity of the real repairable systems need models best approximating the engineering reality and capturing up the physical intrinsic underlying mechanisms of the repairable systems. The reliability engineering and maintenance management fields need efficient, reflective, good approximate models, and practical models.

Practicality requires that the models can firmly capture up the impacts of operation and repair or maintenance on the reliability of a repairable system. To address this question, we need to examine the reliability concept of a system more closely in the interest from engineering and management. Engineering speaking, the concept of system reliability can be stated as the performance or quality measure associated with the dynamic changes of the system state space $S$. Such system performance measures can be represented in a variety of indices, for example, 
stress, pressure, load, availability, mean time between failures, reliability, intensity function etc. From a holistic view of point, a state description and its dynamic changes should guide us to all of our modelling efforts for repairable systems (including non-repairable systems as a special case).

One example to illustrate such state space changes to repairable system modelling is the work by Lawless and Thiagarajah [58], in which they considered a CIF (Conditional Intensity Function) of the form

$$
v\left(t \mid \mathrm{A}_{t}\right)=e^{\underline{\theta^{\prime}} \underline{\underline{z}}(t)}
$$

where $\underline{z}(t)=\left(z_{1}(t), \ldots, z_{p}(t)\right)$ ' is a vector of functions that may depend upon both system operating time $t$ and system operating/failure/repair(Corrective Maintenance) and system operating history $H_{t}$ and $\underline{\theta}=\left(\theta_{1}, \ldots, \theta_{p}\right)$ ' is a vector of unknown parameters. It is fairly clear that the system state is reflected in an aggregate manner via the log-linear form $\underline{\theta}{ }^{\prime} z(t)$. To seek a little more intuitively, we can look at the CIF forms of Cox and Lewis' model as examples:

$$
\rho(t)=\exp (\alpha+\beta t)
$$

and the power law

$$
\rho(t)=\alpha t^{\beta}
$$

Then the same-as-old process can be represented as $\underline{z}(t)=1(t), \underline{\theta}=(\alpha, \beta)$, and $\underline{z}(t)=(1, \log t), \underline{\theta}=(\log \alpha, \beta)$ ' and the same-as-new process can be represented as

$$
\begin{aligned}
& \left.\underline{z}(t)=(1, u(t)){ }^{\prime}, \underline{\theta}=(\alpha, \beta)\right)^{\prime} \text { and } \underline{z}(t)=(1, \log u(t)){ }^{\prime}, \underline{\theta}=(\log \alpha, \beta)^{\prime} \text { where } \\
& u(t)=t-t_{N(t-)} .
\end{aligned}
$$

Table 2 summarised the above results. 
http://orion.journals.ac.za/

\begin{tabular}{|l|l|l|l|}
\hline Regime & State space & $\rho(t)=\exp (\alpha+\beta t)$ & $\rho(t)=\alpha t^{\beta}$ \\
\hline Same-as-new & $\underline{\theta}$ & $(\alpha, \beta)^{\prime}$ \\
& $\underline{z}(t)$ & $(1, \mu(t))^{\prime}$ & $(\log \alpha, \beta)^{\prime}$ \\
& $\underline{\theta}$ & $(\alpha, \beta)^{\prime}$ & $(1, \log \mu(t))$ \\
\hline Same-as-old & $(1, t)^{\prime}$ & $(\log \alpha, \beta)$ \\
& $\underline{z}(t)$ & $(1, \log t)^{\prime}$ \\
\hline
\end{tabular}

Table 2: State Space for Cox \& Lewis and Power Law

Stimulated by the developments in the reliability engineering literature, the repairable system modelling issue is in nature the study of the formalism and the behaviour of the (set-valued) stochastic process

$$
\left\{S_{t}, t \in \mathfrak{R}^{+}\right\}
$$

It is very intuitive that developments on repairable system modelling in the literature reflect the different angles of looking at the system state space or the functional of the state space. For example, the state space for CIF model proposed by Lawless and Thiagarajah [58] can be represented as

$$
S_{t} \triangleq \underline{\underline{z}}(t), t \in \mathfrak{R}^{+}
$$

and therefore the stochastic process

$$
\left\{\left(\underline{\theta}^{\prime} \underline{z}(t), \mathrm{A}_{t}\right), t \in \mathfrak{R}^{+}\right\}
$$

specifies Lawless and Thiagarajah [58] CIF model.

Therefore the task of this paper is to review the recent quick growth areas in repairable system modelling, particularly the stochastic processes behind them and reflecting the underling engineering mechanism. Intuitively, a stochastic process $X=\left\{X_{t}, t \in \mathfrak{R}^{+}\right\}$is a family of random variables defined on the same probability space $(\Omega, \mathrm{A}, \mathrm{P})$. The most commonly 
mentioned stochastic processes $X$ mentioned in the classical reliability engineering literature are renewal processes, Poisson processes, Markov Chains, Semi-Markov processes and point processes.

Point processes is defined with less restrictive assumptions although it is lack of some closed form theoretical results as others in general. In a certain sense, a point process should be regarded as a simple model for modelling repairable systems, although the language describing it is difficult at the first glance. However, applications of point processes into repairable system modelling is not uncommon, for example, Baxter, Kijima and Tortorella [56], Finkelstein [30-31], Guo and Love [41], Last and Szekli [55] and [56] and Lawless and Thiagarajar [58].

A point process $\left\{N_{t}, t \in \mathfrak{R}^{+}\right\}$is said to admit a stochastic intensity $\left\{v(t), t \in \mathfrak{R}^{+}\right\}$with respect to a filtration (history) $\left\{F_{t}, t \in \mathfrak{R}^{+}\right\}$

$$
v(t)=\lim _{h \rightarrow 0} \frac{E\left[N_{t+h}-N_{t} \mid F_{t}\right]}{h}, t \in \mathfrak{R}^{+}
$$

Let $T_{1}, \ldots, T_{n}$ denote the occurrence times in a point process $\left\{N_{t}, t \in \mathfrak{R}^{+}\right\}$ and $X_{n}=T_{n}-T_{n-1}$. Then the stochastic intensity of point process $\left\{N_{t}, t \in \mathfrak{R}^{+}\right\}$with respect to its natural filtration $\left\{F_{t}^{N} \triangleq \sigma\left(N_{s}, s \leq t\right), t \in \mathfrak{R}^{+}\right\}$is

$$
v(t)=\frac{f^{(n+1)}\left(t-T_{n}\right) \vartheta_{\left(T_{n}, T_{n+1}\right)}(t)}{1-\int_{0}^{t-T_{n}} f^{(n+1)}(u) d u}, t \in \mathfrak{R}^{+}
$$

where $f^{(n+1)}$ is a random function satisfying

$$
F_{X n \mid T_{1}, \ldots, T_{n}}(x)=\operatorname{Pr}\left[X_{n+1} \leq x \mid T_{1}, \ldots, T_{n}\right]=\int_{0}^{x} f^{(n+1)}(u) d u, \forall x \geq 0
$$

and 


$$
\vartheta_{A}(\omega)=\left\{\begin{array}{lr}
1 & \text { if } \omega \in A \\
0 & \text { otherwise }
\end{array}\right.
$$

Or equivalently,

$$
\begin{aligned}
& h_{n}\left(x \mid T_{1}, \ldots, T_{n}\right)=\frac{f^{(n+1)}\left(x-T_{n}\right)}{1-\int_{0}^{x-T_{n}} f^{(n+1)}(u) d u}, x \in\left[T_{n}, T_{n+1}\right), \\
& v(t)=\sum_{n=1}^{\infty} h_{n}\left(t \mid T_{1}, \ldots, T_{n}\right) \vartheta_{\left[T_{n}, T_{n+1}\right]}(t), t \in \mathfrak{R}^{+} .
\end{aligned}
$$

and

We should notice here the intensity $v(t)$ (ROCOF) is not the hazard function which is $h_{1}(t)$, the "first" piece of $v(t)$ only. The total or global accumulated hazard (compensator actually) is

$$
A(t)=\int_{0}^{t} v(u) d u=H_{n+1}\left(t-T_{n} \mid T_{1}, \ldots, T_{n}\right)+\sum_{i=1}^{n} h_{i}\left(T_{i} \mid T_{1}, \ldots, T_{i-1}\right), t \in\left[T_{n}, T_{n+1}\right)
$$

and $h_{n+1}\left(t-T_{n} \mid T_{1}, \ldots, T_{n}\right)$ is the partial or local accumulated hazard.

About counting point processes, it is worth to mention two fundamental facts. First, we notice that a counting process $\left\{N_{t}\right\}$ can be decomposed into two parts: a system term, represented by the compensator $\left\{A_{t}\right\}$, a smoothly varying and predictable process, and, a pure "noise" term represented by a martingale $\left\{M_{t}\right\}$ with a unpredictable zero-mean

$$
E\left(d M_{t} \mid F_{t-}\right)=0
$$

i.e.,

$$
M_{t}=N_{t}-A_{t}
$$


Secondly, we notice a local Poisson character of a counting process. In other words, under certain conditions (particularly, the continuity and predictability of the compensator $A(t)$ are assumed) the conditional mean and the conditional variance of the increment are equal, i.e.,

$$
E\left(d N(t) \mid F_{t-}\right)=\operatorname{var}\left(d N(t) \mid F_{t-}\right)=d A(t),
$$

where

$$
d N(t)=N(d t) \stackrel{\Delta}{\triangleq} N((t+d t)-)-N(t-) .
$$

These remarkable simple facts will not only help us to understand the basic feature of the counting processes but also provide some clues to estimate the parameters of counting point processes.

In order to have a clear structure of this paper, we list the remaining sections and the models reviewed in Table 3.

\begin{tabular}{|l|l|l|}
\hline Section & $\begin{array}{l}\text { Stochastic processes } \\
\text { reviewed }\end{array}$ & Basic element of $S_{t}$ \\
\hline 2 & intrinsic age processes & $H_{i}(t)$ \\
\hline 3 & virtual age processes & $v_{t}$ \\
\hline 4 & $\begin{array}{l}\text { proportional intensity } \\
\text { processes }\end{array}$ & $\underline{z}_{t}$ \\
\hline 5 & shock and wearing processes & $X_{i}=\alpha_{0}+\sum_{j=1}^{N_{t}} Y_{i}$ \\
\hline 6 & other models mentioned in & \\
\hline
\end{tabular}

Table 3: Models review allocation

In Section 2, we briefly review the newly appeared intrinsic age model because this model provides some deep insights in the failure mechanism of repairable system and the simple exponential distribution feature. The intrinsic age process may provide a general frame for repairable system modelling because it captures some locality features under Markovian state 
assumptions. Section 3 is used to discuss the age related generalised models, for example, the popular virtual age models initiated by Kijima, which in nature is a kind of (or a transformation) of "accelerated life" model. Because of a certain mathematical simplicity and tractability property, the virtual age of a repairable system can be viewed as a part of the state space of the repairable system or an index of state space (like a "bioclock" in human body system). Virtual age models are probably the deepest research topic and hence created a relatively large portion of the generalised repairable models in reliability engineering, or in a more general sense operations research literature. Section 4 is reserved to discuss the condition monitoring related models, particularly proportional covariate models as a repairable system model. The original version of proportional hazard model initiated by Cox [20] might not be intended to consider the repairable system. However, researchers have noticed that proportional covariate model is a way to capture system state changes during the system operations and maintenance. Therefore modelling imperfect repair should not be regarded as a leisurely discussion after dinner and the idea to model general repair by PI (proportional intensities) covariates is very innovative. Further we review the general covariate models as a repairable system modelling option which can be treated as a natural extension from PI model. Section 5 reviews the compounding processes and applications, say, cumulative damage and wearing deterioration models in recent reliability engineering literature, particularly the delay-time models proposed by Christer and Wong. Finally, in Section 6, we will mention a few remarks and point out the some potential research directions for repairable system modelling.

\section{INTRINSIC AGE PROCESSES}

It is in general a fundamental reality that to identify the formality of a state space process and the probability law is not a trivial task for a reliability engineers and managers. Therefore it would be very helpful to have some guideline to have some prior forms in hand for repairable system modelling. Furthermore, it is desirable to have a general form clearly including the physical mechanism in it.

Lawless [57] pointed out "hazard function represents an aspect of a distribution that has direct physical meaning, and the information about the nature of the hazard function is helpful in selecting a model". It is a well-known fact that hazard rate is an intrinsic index of nonrepairable system in reliability engineering literature. Recently, Finkelstein [32] pointed out, 
hazard rate is so important and convenient in lifetime data analysis because it is already a conditional characteristic. Furthermore, we notice that for a minimal repair process, the intensity function enjoys a simple link to the hazard function. Conceptually, the hazard function is the propensity to fail shortly after $x$, given the non-repairable system is successfully functioning up time $x$, or mathematically,

$$
h(x)=\lim _{\Delta x \rightarrow 0} \frac{\operatorname{Pr}\left[x \leq X_{1}<x+\Delta x \mid X_{1} \geq x\right]}{\Delta x} .
$$

Further, we notice that the "integrated hazard function" or "accumulated hazard function", $H(x)$, which is a non-decreasing function of $x$ is actually a quantity measuring the accumulated state change due to non-repairable system operation and wear out ,(more accurately speaking accumulated hazard function is a function of the system state space), because the system reliability function is

$$
R(x)=e^{-H(x)}=\exp \left(-\int_{0}^{x} h(u) d u\right)
$$

For a non-repairable system, the higher the hazard function is, the higher the accumulated hazard and the lower the reliability of the system will be, over a given time interval.

For a repairable system, after $n$ failure-repair activities, the system reliability does not depend upon the "total or global" accumulated hazard (compensator), $A(t)$, rather depend upon the "partial or local" accumulated hazard, $H_{n}(x)$. Notice that role of the maintenance or repair is intending to remove the faults of the system or to improve the system so that the system local (conditional) accumulated hazard (not the hazard in general) can be improved. We noticed that the most likely time a car needs repair is immediately after it has been "repaired") is decreased and accordingly the system local (conditional) reliability is enhanced. In other words, repair or maintenance action shrinks the value of system local accumulated hazard in terms of improving the conditional hazard function and hence enhances the system performance. To emphasise the role of (local or conditional) accumulated hazard, it was given a term intrinsic age of a system as its identity. 
Özekici [69] investigated the intrinsic age of a system operating under a random environment. It is assumed that the process $\left\{\left(\xi_{n}, T_{n}\right), n \geq 0\right\}$ is a Markov renewal process on the state space $S=E \times \mathfrak{R}^{+}$with a semi-Markov Kernel $Q$ :

$$
Q(i, j, x)=\operatorname{Pr}\left[X_{n+1}=j, T_{n+1}-T_{n} \leq x \mid X_{n}=i\right], i, j \in E, x \geq 0
$$

Let $L$ represent the lifetime of the system and $A_{x}$ be the intrinsic age at time $x \geq 0$. The reliability of the system

$$
R_{i}(t)=\operatorname{Pr}[L>t \mid Y=i], i \in E, t \geq 0
$$

with conditional hazard function $h_{i}(t)$ and conditional accumulated hazard

$$
H_{i}(t)=\int_{0}^{t} h_{i}(u) d u
$$

and

$$
R_{i}(t)=e^{-H_{i}(t)}
$$

From the above arguments, Özekici defined an intrinsic clock of the system as

$$
A_{t}=H_{i}(t)
$$

In terms of the system intrinsic age, the lifetime

$$
L=\inf \left\{s \geq 0 ; \Pi>A_{s}\right\}
$$

if the intrinsic age of a system is denoted as random quantity $\Pi$. Furthermore, the system reliability

$$
\begin{aligned}
R_{i}(t) & =\operatorname{Pr}[L>t \mid Y=i] \\
& =\operatorname{Pr}\left[\Pi>A_{t} \mid Y=i\right] \\
& =e^{-A_{t}} .
\end{aligned}
$$


Accordingly, the reliability of the system can be described in terms of the intrinsic age processes $\left\{\Pi_{t}, t \in \mathfrak{R}^{+}\right\}$and the probability law governing the stochastic process. A great simplicity in the intrinsic age process research is that for any given environment state $i \in E$, the system has an exponential distributed intrinsic lifetime with parameter 1. As a matter of fact, the intrinsic age is simply the transformed (by conditional accumulated hazard $H_{i}(t)$ ) real lifetime under environment state $i \in E$, just like that in Poisson processes theory the transformed time of sojourn life time in a non-homogeneous Poisson process under compensator is a homogenous Poisson process with unit parameter.

Formally, let

$$
H_{i}^{-1}(x)=\inf \left\{t \geq 0 ; H_{i}(t)>x, i \in E\right\}
$$

Then the intrinsic age process $\left\{\Pi_{t}, t \in \mathfrak{R}^{+}\right\}$is a non-decreasing continuous stochastic process

$$
\Pi_{T_{n+s}}=\left\{\begin{array}{cl}
\Pi_{X_{n}}\left(H_{X_{n}}^{-1}\left(A_{T_{n}}\right)+s\right) & \text { if } A_{T_{n}}<\alpha_{X_{n}}, \\
A_{T_{n}} & \text { if } A_{T_{n}} \geq \alpha_{X_{n}},
\end{array} \quad \text { with } X_{n} \in E\right.
$$

where

$$
\begin{aligned}
& a_{i}=\lim _{t \rightarrow \infty} H_{i}(t), i \in E, \\
& s \leq T_{n+1}-T_{n}, n \geq 0 .
\end{aligned}
$$

It is very clear that the intrinsic age process was originally aimed at modelling a (nonrepairable) system under a semi-Markov stochastic environment. However, if treating a repair improvement to the system as changing a system "environmental state" from $i$ to $j, i, j \in E$ (with the assumption that the state space $E$ is still discrete, although far from reality), and a state-related lifetime distribution is assumed for every state, then the intrinsic age process can be a convenient stochastic model for a repairable system. The discrete state space $E$ is less realistic but is widely used in the repairable system modelling practices, because semi-Markov processes is not something new in reliability engineering literature. The only problem in the 
intrinsic age process modelling is the specification of the state space $E$ because of the crisp set definition which excludes the possible evolution among points in the sample space. It will be much desirable to develop a fuzzy Markov renewal framework in the future study.

\section{VIRTUAL AGE PROCESSES}

Virtual age can be understood as an aggregate index of the system state space $S$. Researchers have long noticed that the chronological age as an element of the state space $S$ does not quite often reflect the instinct of the system. For example, three cars of the same make and started operation at the same time, say, on January 1,1998 , by the $31^{\text {st }}$ December, end of year 2000 , two car's mileage meter both indicated $100,000 \mathrm{~km}$, and the third car only recorded $7500 \mathrm{~km}$. It is obvious three cars have the same chronological age, 2 years old. But the third car with $7,500 \mathrm{~km}$ mileage record will be more reliable than the first two cars with 100,000 km mileage record. Even for cars with same records, different driving behaviour and road conditions may cause the same mileage cars to have different performance in the future. In order to recognize such an intrinsic character of a system, just like the bioclock of human beings, researchers named it a virtual age.

The following table lists the important virtual age models developed during last decade.

\begin{tabular}{|l|l|l|}
\hline Model & $\begin{array}{l}\text { Virtual age after repair } \\
v\left(t_{i}+0\right)\end{array}$ & Authors \\
\hline Model I & $v\left(t_{i-1}\right)+\left(1-\delta_{i}\right) x_{i}$ & Kijima (1989) \\
\hline Model II & $\delta_{i}\left(v\left(t_{i-1}\right)+x_{i}\right)$ & Kijima (1989) \\
\hline Improvement factor & $v\left(t_{i-1}\right)+x_{i}-d$ & Stadje \& Zuckerman (1991) \\
\hline General & $\phi\left(v\left(t_{i-1}\right)+x_{i}\right)$ & Finkelstein (1993) \\
\hline Unified & $\left(1-\omega_{i}\right) v_{\left.t_{i-1}\right)}+\left(1-\delta_{i}\right) x_{i}$ & Guo, Love \& Bradley (1995) \\
\hline Generalized & $\psi\left(v\left(t_{i-1}\right), x_{i}\right)$ & $\begin{array}{l}\text { Makis (1995), } \\
\text { Dagpunar (1998) }\end{array}$ \\
\hline Universal & & \\
\hline
\end{tabular}

Table 4: Virtual age models 
Kijima [49] argued that if the virtual age of the system immediately after $(n-1)^{s t}$ repair, the $n^{\text {th }}$ failure time of the system follows a distribution:

$$
\operatorname{Pr}\left[X_{n} \leq x \mid V_{n-1}=y\right]=\frac{F(x+y)-F(y)}{1-F(y)}
$$

where

$$
F(x)=\operatorname{Pr}\left[X_{1} \leq x\right] .
$$

Essentially this formula has facilitated the probabilistic foundation for all the virtual age model developments. As to the forms of the virtual age models, laid down by Kijima [49], $n^{\text {th }}$ repair improvements are basically measured by some functionals of the virtual age immediately after $(n-1)^{s t}$ repair, $V_{n-1}$ and the $n^{\text {th }}$ functional time, $x_{n}$. Kijima Model I is a linear combination of $V_{n-1}$ and $x_{n}$ with coefficients 1 and $\left(1-\delta_{n}\right)$ respectively. In Model I, repair work fixes the wearing out and damages between time $\left(t_{n-1}, t_{n}\right)$, with the intention that virtual age increment is proportional to functioning time. Kijima virtual age Model II implies that repair work fixes all the wearing out and damages unfixed prior to the $(n-1)^{s t}$ repair and those between time $\left(t_{n-1}, t_{n}\right)$ with the intention that virtual age increment is proportional to all the accumulated virtual age, $v\left(t_{n-1}\right)+x_{i}$. The later virtual age model developments in certain sense are extensions along these two different angles. Finkelstein's general model [29] is an extension to Kijima's Model II, while Makis and Jardine's [67] generalised model generalised Kijima's Model I. As to the unified model proposed by Guo, Love and Bradley [42] can be regarded as a linear function version of Makis and Jardine's generalised model. Definitely, the unified model can facilitate the merging point for the Kijima's two models. The unified model gives merely some mathematical conveniences and we can extend it further into a non-linear form: $\varpi\left(\varsigma\left(v\left(t_{i-1}\right)\right)+\varphi\left(x_{i}\right)\right)$, named universal virtual age model can be developed.

Virtual age models are physically intuitive and mathematically useful but under a strong assumption: repair does not change the system's probabilistic structure, rather its virtual ages. This assumption is logically acceptable and physically unrealistic because even adjustments on a brand-new system will change the system parameter setting and accordingly change the 
failure probabilistic structure. Practically, repair improvement even as small as a percent reduction in virtual age reduction would eventually make the repaired system significantly different from the same-as-old system. Since 1992, Guo and Love [39], Guo and Bradley [40] had a series of attempts to estimate the repair improvement. However their practices exposed that the virtual age models do not often provide good statistical inference.

It is quite engineering intuitive that virtual age model in nature transforms the repair improvement into system age recovery (or shifts the age of system to the left along the time axis). Combining such an age recovery idea and the local Poisson property of the general point process, many researchers have intensively investigated the optimal maintenance policies, for example, Kijima [49] and [51], Stadje and Zuckerman [85], Finkelstein [29] and [30], Markis and Jardine [67], Love and Guo [63] and [65], Love, Zhang, Zitron and Guo [66], Li and Shaked [59], Jiang, Cheng and Markis [48], Chen and Feldman [14] etc.

However a serious question arises practically: how much improvement from repairs? Our simulation results show that even with as little as one percentage improvement at each repair, the system will quickly move away from its baseline intensity function. Whitaker and Samaniego [93] and Guo and Love [39] investigated the statistical inference procedures in terms of virtual age model. A chilly fact about the statistical analysis involving the virtual age modes is that the estimator of $\delta$ (average repair improvement) is not stable and sometimes the variance is very large, such that there is no statistical significance. One of the reasons is that the non-linearity in $\delta$ which increases its power by one after each repair-piece-wise polynomial in $\delta$. Actually the virtual age structure is an external imposition on the assumed system probabilistic structure and it is not the instinct part of the point process causing the semi-positive definite second derivative matrix. Non-linear dynamics may cause a chaotic behaviour here. Therefore the properties of general failure/repair processes have gained more attention in recent years, for example, Boland and El-Neweihi [11], Dagpunar [21], Gong, Pruett, Tang [36], Kijima [51], Li, Shi, and Cao [60], Love and Guo [63], Guo and Love [41] and [43], and Stadje and Zuckerman [85] etc.

It is worthwhile to emphasise here that one of the exciting achievements in virtual age developments during the last five years is due to Last and Szekli [56] who successfully 
derived a general form of age model by a marked point process dynamics (Last and Brandt [55]).

The successive accumulated hazard functions for distributions of the sojourn times (interpoint distances) of $N_{t}$ on the filtration $\left\{F_{t}^{N}, t \in \mathfrak{R}^{+}\right\}$is

$H_{n+1}\left(t \mid\left(t_{i}, z_{i}\right), i=1, \ldots, n\right)=\int_{0}^{t} \frac{\operatorname{Pr}\left[X_{n+1} \in d s \mid\left(T_{i}, Z_{i}\right)=\left(t_{i}, z_{i}\right), i=1, \ldots, n\right]}{\operatorname{Pr}\left[X_{n+1} \geq s \mid\left(T_{i}, Z_{i}\right)=\left(t_{i}, z_{i}\right), i=1, \ldots, n\right]}, n \geq 1$,

where $\Phi^{\triangleq}\left\{\left(T_{n}, Z_{n}\right), n \geq 0\right\}$ is the marked point process with non-negative random variable sequence called marks $\left\{Z_{n}, n \geq 0\right\}$. For $n=1$, the accumulated hazard function

$$
H_{1}(t)=\int_{0}^{t} \frac{\operatorname{Pr}\left[X_{1} \in d s\right]}{\operatorname{Pr}\left[X_{1} \geq s\right]}, t \geq 0
$$

It is obvious that the conditional hazard function of sojourn times is

$$
h_{n+1}\left(t \mid\left(t_{i}, z_{i}\right), i=1, \ldots, n\right)=\lim _{s \rightarrow 0} \frac{\operatorname{Pr}\left[X_{n+1} \in d s \mid\left(T_{i}, Z_{i}\right)=\left(t_{i}, z_{i}\right), i=1, \ldots, n\right]}{\operatorname{Pr}\left[X_{n+1} \geq s \mid\left(T_{i}, Z_{i}\right)=\left(t_{i}, z_{i}\right), i=1, \ldots, n\right]}
$$

and thus the stochastic intensity with respect to the internal filtration $\left\{F_{t}^{\Phi}, t \in \mathfrak{R}^{+}\right\}$

$$
\lambda(t)=\sum_{n=0}^{\infty} \vartheta_{\left(T_{n}, T_{n+1}\right)}(t) h_{n+1}\left(t-T_{n} \mid\left(T_{i}, Z_{i}\right), i=1, \ldots, n\right)
$$

and thus the compensators

$$
A(t)=H_{n+1}\left(t-T_{n} \mid\left(T_{i}, Z_{i}\right), i=1, \ldots, n\right)+\sum_{i=1}^{n} H_{i}\left(X_{i} \mid\left(T_{j}, Z_{j}\right), j=1, \ldots, i-1\right)
$$

which is just the total hazard accumulated by the system up to time $t$. 
The virtual age process $\left\{V_{t}, t \in \mathfrak{R}^{+}\right\}$

$$
V_{t}^{\underline{\Delta}} V_{n}+t-T_{n}, T_{n} \leq t<T_{n-1}
$$

with

$$
\begin{aligned}
& V_{n} \triangleq\left(1-Z_{n}\right)\left(V_{n-1}+X_{n}\right), \\
& V_{0}=0, V_{1}=\left(1-Z_{1}\right) T_{1},
\end{aligned}
$$

where $Z_{n}$ is the degree of repair received by the system at the time of $n^{\text {th }}$ failure,

$$
X_{n}=T_{n}-T_{n-1}
$$

The distribution of the time until the next failure admits

$$
r_{n+1}(y)^{\underline{\Delta}} r\left(V_{n}+y\right), t \geq 0, n \geq 0
$$

where the failure intensity $r$ is a positive real-valued function $r: \mathfrak{R}^{+} \rightarrow \mathfrak{R}^{+}$. It is obvious that the virtual age process $\left\{V_{t}, t \in \mathfrak{R}^{+}\right\}$catches the system state changes during the system functioning and repairing but it is not directly observable in general. The observations of marked point process are the pairs $\left\{\left(T_{n}, Z_{n}\right), n \geq 1\right\}$. In general, the degree of repair at the $n^{\text {th }}$ failure $Z_{n}$ depends upon the whole history of functioning and repairs up to the $n^{\text {th }}$ failure time $T_{n}$, i.e.

$$
Z_{n}=f\left(T_{1}, Z_{1}, \ldots, T_{n-1}, Z_{n-1}, T_{n}\right)
$$

The nature of random sequence $\left\{Z_{n}, n \geq 1\right\}$ associated with distributions $\left\{D_{n}(z)\right\}$ specifies the properties of the virtual age process $\left\{V_{t}, t \in \mathfrak{R}^{+}\right\}$. Denote $\left\{U_{n}\right\}$ as i.i.d. uniformly distributed random variables on $[0,1]$. Table 5 summaries the impacts of degree of repair sequence $\left\{Z_{n}, n \geq 1\right\}:$ 


\begin{tabular}{|c|c|c|c|c|}
\hline & Degree of repair & Virtual age & Model & System \\
\hline $\mathrm{i}$ & $Z_{n} \equiv 1$ & $\mathrm{~T}$ & Same-as-new & Failure rate $r(t)$ \\
\hline ii & $Z_{n} \equiv 0$ & $T_{n}+t$ & Same-as-old & Intensity $v(t)$ \\
\hline iii & $Z_{n} \equiv \begin{cases}1 & \text { with probability } p \\
0 & \text { with probability } q\end{cases}$ & $\left(1-Z_{n}\right) D_{n}+t$ & $\begin{array}{l}\text { Barlow \& } \\
\text { Proschan }\end{array}$ & $(r(t), p)$ \\
\hline iv & $Z_{n} \equiv \frac{\left(1-K_{n}\right) X_{n}}{K_{1} X_{1}+\ldots+K_{n} X_{n-1}+X_{n}}$ & $\sum_{i=1}^{n_{t}} K_{i} X_{i}+t$ & $\begin{array}{l}\text { Kijima } \\
\text { Model I }\end{array}$ & $\left(r(t), F_{k_{n}}\right)$ \\
\hline $\mathrm{V}$ & $Z_{n}=1-K_{n}$ & $\sum_{i=1}^{n_{t}}\left(\begin{array}{c}n_{t}-j+1 \\
\prod_{j=i}^{j+1}\end{array}\right) X_{i}+$ & $\begin{array}{l}\text { Kijima } \\
\text { Model II }\end{array}$ & $\left(r(t), F_{k_{n}}\right)$ \\
\hline $\mathrm{Vi}$ & $Z_{n}=D_{n}^{-1}\left(U_{n}, T_{n}\right)$ & & Block et al. & $(r(t), p(t))$ \\
\hline Vii & $Z_{n}=D_{n}^{-1}\left(U_{n} ; T_{1}, Z_{1}, \ldots, T_{n-1}, Z_{n}, T_{n}\right)$ & & Shaked et al. & $(r(t), p(t))$ \\
\hline Viii & $\begin{array}{l}Z_{n} \frac{g\left(V\left(T_{n}-\right)\right)}{V\left(T_{n}-\right)} \\
\text { function } g(x) \leq x\end{array}$ & $\sum_{i=1}^{n_{t}}\left(\prod_{j=i}^{n_{t}-j}\left(1-Z_{j}\right)\right)$ & $\begin{array}{l}\text { Stadje \& } \\
\text { Zuckerman }\end{array}$ & $(r(t), g)$ \\
\hline
\end{tabular}

Table 5: Virtual age models covered by virtual age processes

The marked point processes development unifies almost every existing simple virtual age model under either failure repair or planned repair regimes. However, the difficulties in estimating the repair effects do not disappear yet. Probably some non-parametric or semiparametric estimation on repair effects can be done in terms of semi-martingale inference, say, Rao [73]. Our experiences showed that the artificial imposed mathematical structures always cause series problems in statistical inference and hypothesis testing. But we also realise that some stochastic processes, for example, Levy processes, including the special cases, the stable processes, which are attracted more attention in mathematical modelling because such class permits the jumps intrinsically, for example Bertoin [10] and Zolotarev [95]. 


\section{PROPORTIONAL INTENSITIES PROCESSES}

It is fair to say that both the intrinsic age processes and virtual age processes modelling of the repairable system have addressed the state space issue from mathematical view of point because such state parameters are abstract and invisible mathematical descriptors. It is unfortunate situation that reliability engineering modelling developments sailed away from the physical features from engineering practices. Just as Scarf [75] pointed out "the modellers themselves take a low priority than understanding the process of interest of decision maker. This has not often been the case in the past where, even with the best intentions, so called applications and case studies appear to have been motivated by the need to find an application for a particular model, rather than by the solution of the problem of the interest to the engineer or manager." Repairable system modelling should be reliability engineering rather reliability mathematics. Without full utilisation of the engineering information, mathematics will not generate it maximal power and its potential.

Engineeringly speaking, the concept of reliability of a system should be interpreted as the engineering capacity of a system completing its engineeringly specified functionality within the specified time under its engineeringly specified conditions. Therefore it is important to explore meaning of the four basic elements underlying the reliability: three "specifications" and one "capacity". With a thoroughly understanding of the concept we can reflect the underlying engineering mechanism in our modelling exercises. Today we are very rich in many models with excellent mathematical structures but very poor in engineering links to the information of the functioning system.

i. The "capacity". The term of capacity (or operability) should quantify the system performance. It should be emphasised that the quantification of capacity for nonrepairable and repairable systems differs. In traditional reliability framework, the capacity is often quantified from different standing points. For example, life time, might be the most frequently used term from physical side. From probabilistic point of view, hazard function is a term used for the non-repairable system. While terms such as average lifetime and "availability", mean time to failure (MTFF) etc. are from physical side and terms intensity, rate of occurrences and conditional hazard function are from probabilistic point. Actually, the term capacity should be a quantity measure or index directly linked to the physical mechanism of a functioning system, but 
researcher in reliability engineering has paid too little attention to the physical mechanism side. Because a complex system today is more and more modularised, the failure of a system in nature comes from one or more modules and therefore the repair (corrective maintenance) or maintenance (preventive maintenance) is often a module replacement. Probabilistically speaking, it is important to be aware of that the phenomena of system malfunctions as chance events. Chance event is a break down of the law of causality because of the lack of some conditions under which the event occurrence is inevitable. Therefore it is senseless to discuss the capacity of a single system. It only makes sense when evaluating the reliability by observing "repeated experiments" of the same type of the specific interested system. Logically, it is the break down of the law of causality. Hence the capacity description in reliability concept has a statistical sense and is quantified in terms of probability in the traditional reliability theory.

ii. The "specified conditions". The external or environmental conditions of a system are referred to as the "specified conditions". These conditions are usually including the system applying conditions, maintaining conditions, the environmental conditions, and the operating conditions of a system. The reliability of the system may vary substantially if the conditions vary differently. Particularly we must be aware that any machinery system, no matter how advanced it is, is operated by human beings directly or indirectly. Human error is the highest contributing factor toward the changes in system environmental conditions. However, human error is often not traceable and therefore is ignored from modelling efforts. As a matter of fact, the specified conditions are fuzzy and vague in nature and their records are full of inaccuracy.

iii. The "specified functionality". In traditional reliability treatment, the functionality of a system is described by various (designated) functional specifications. If the functionality of the system acts within its specifications, it is said to be functional otherwise malfunction (or losing its specified functionality). It is quite obvious that the traditional definition of system functionality is a typical "yes" or "no" two-valued logical thinking. In reality, "evolution" or "transition" states exist between the two extreme states. The evolution is simply the break down of the law of excluding the middle. 
iv. The "specified time". Without time, there is no sense to talk about reliability, except for one-shot items. Whenever the reliability is discussed, it is required to discuss the reliability within a specified time. Time can be described deterministic or random crystal clear or a fuzzy number. In classical analysis, time is in general retreated as an explanatory variable with no taste, no colour, no direction and a non-reversible uniform flow of real number system. However, as Guo and Frerichs [43] pointed out, whenever a human (operator) is involved the behaviour of time variable will become complicated and thus the time non-uniformity impacts on human body system should be carefully reflected in modelling efforts.

The engineering emphasis on reliability modelling here should be actually reflected in the related engineering or operating information combining into the repairable system modelling efforts, i.e., linking to the "three specified" and "one capacity" features of the system reliability to the formalism. It is fairly clear that the basic definition of hazard function merely reveals the aggregate measure of the four aspects of system reliability, mathematically rather than engineeringly. As the quick advancements in science and technology equipment become more and more complicated and requirements for manufacturing operating performances also become higher and higher. Inevitably, monitoring some operation related indices (parameters, variables) over time and take necessary engineering actions (e.g., adjustments, corrective maintenance, preventive maintenance etc.) whenever those indices move away from their engineering specified ranges. During last two decades, combining monitored operating conditions into system analysis and modelling efforts became evident.

The semi-parametric regression model, called as proportional hazard (PH) model

$$
h(t ; \underline{z})=h_{0}(t) g(z)
$$

was first initiated by Cox [20] and quickly sparkling medical applications during 1980s but the industrial applications of PH model were developed after late 1980s, say, Dale [22], Jardine, Anderson and Mann [47], Love and Guo [61], [62], and [63], Percy, Kobbacy and Ascher [70] etc. These developments can be regarded as an passive application of system modelling. The term of a "passive" application here means simply that the covariate 
information is used for monitoring the system functioning state changes so that the system performance (or capacity) can be judged and decision on the maintenance action can also be justified accordingly. Such information is partial and incomplete in the sense that covariates reflecting operating conditions are monitored during the functioning and repair resetting stages but there is no covariate reflecting repair or maintenance impacts. Kumar and Klefsj [52] gave an excellent review on the industrial applications of PH modelling before 1994.

The idea of active modelling repairable systems via PI (PH) models was recognised by Kumar [53]. The term "active" means that the repair or maintenance actions can be clearly reflected in the proportionality as a part of covariate structure in the models, for example, Kumar and Westberg [54].

From the description of the virtual age models, it is clear that under virtual age model assumptions the maintenance impacts do not change the form of the system intensity function but shift the intensity "block" horizontally along the time axis. Contrary to virtual age model, the proportional intensity modelling of the repairable system assume that maintenance impacts do not change the form of the baseline system intensity function but shift the intensity "block" vertically along the intensity axis. To reflect such a vertical shift (repair impacts) in a proportional form, we can look at the basic form of $\mathrm{PH}$ model

$$
v(t ; \underline{z})=v_{0}(t) \exp \left(z^{\prime} \underline{\theta}\right)
$$

The intensity function is determined by "local" or conditional hazard anyway, thus the proportionality concerned here is essentially a local property. Kumar [53] pointed out the extended proportional hazard models, particularly the stratified proportional hazard models, can be used to capture the "jumps" due to repairs.

A repairable system has $j$ different strata if its state can be classified into $j$ groups in accordance to one or more covariates. The hazard function of the system in stratum $j$ can be formed as

$$
v_{j}(x ; \underline{z})=v_{0 j}(x) \exp \left(z^{\prime} \underline{\theta}\right)
$$


The baseline hazard function, $v_{0 j}(x)$, is usually assumed unchanged in the different strata. The likelihood function should be drawn for each stratum and the estimation of the covariate effect, $\underline{\theta}$, by maximising the total likelihood function

$$
L(\theta)=\prod_{j=1}^{r} \prod_{i=1}^{k} L_{j}(\theta)=\prod_{j=1}^{r} \prod_{i=1}^{k} \frac{\exp \left(\underline{\mathbf{z}}_{i j}{ }^{\prime} \underline{\theta}\right)}{\left[\sum_{l, j \in F\left(x_{i j}\right)} \exp \left(\underline{z}_{l j} \underline{\theta}^{\prime}\right)\right] d i}
$$

Some counting process idea is proposed to convert the time variable into strata information, say,

$$
v(t \mid N(t), \underline{z})=v_{0 j}(t) \exp \left(\underline{z}^{\prime} \underline{\theta}\right)
$$

and

$$
v(t \mid N(t), \underline{z})=v_{0 j}\left(t-t_{n(t)}\right) \exp \left(\underline{z}^{\prime} \underline{\theta}\right)
$$

Here $\{N(t), t\}$ is denoted as the failure/repair counting process and $n(t)$ is the number of failures prior to time $t, j$ is the stratum occupied by the system at a moment $t$. This formulation offers a route for repairable system modelling by assuming that a system enters stratum $j$ at the occurrence of $(j-1)$ th failure, $j=1,2, \ldots, r$ and it enters stratum 1 at time $t=0$. General speaking, the idea of Kumar's modelling repair impacts by strata is innovative but imposing some strong structural changes assumption again. Such imposed structure may cause further difficulties in statistical estimation. However, modelling repairable systems in terms of stratified proportional hazards deserves further improvements.

The current conditional hazard functions can be related to previous one by the formula

$$
v_{0, n+1}(t)=v_{0, n}(t) \exp \left(\vartheta_{\left[T_{n}, T_{n+1}\right)}(t) 1 g\left(1-\delta_{n}\right)\right), T_{n} \leq t \leq T_{n+1},
$$

where 


$$
\vartheta_{\left[T_{n}, T_{n+1}\right)}(t)=\left\{\begin{array}{l}
1 \text { if } t \in\left[T_{n}, T_{n+1}\right) \\
0 \text { if } \mathrm{t} \in\left[T_{n}, T_{n+1}\right)
\end{array},\right.
$$

and

$$
\delta_{n} \in[0,1], n \geq 1
$$

Therefore by adding a term $\vartheta_{\left[T_{n}, T_{n+1}\right)}(t) 1_{n}\left(1-\delta_{n}\right)$ in to $\left(z^{\prime} \underline{\theta}\right)$, the new covariate structure can well facilitate a mechanism monitoring both the operating conditions and maintenance impacts which are reflected by the proportionality, although locally. In summary,

$$
v(t ; \underline{z})=v_{0, n}(t) \exp \left(\underline{z}^{\prime} \underline{\theta}\right)
$$

where

$$
\underline{z}_{t}^{\prime} \underline{\theta}=\vartheta_{\left[T_{n}, T_{n+1}\right)}(t) \ln \left(1-\delta_{n}\right)+\underline{z}^{\prime} \underline{\theta}
$$

Notice that the repair or maintenance may cause vertical jumps in intensity function, but it does not destroy the continuity and the predictability properties of th e accumulated intensity and therefore the local Poisson property is still applied here and provides a foundation for statistical estimation and inference.

As to the covariate structure, proportionality is not the only form, for example, the accelerated life model, say, Devarajan and Ebrahimi [25], which is in nature the shift by a factor $\psi(z)$ (similar to virtual age modelling). More general covariate structures were examined by Ciampi and Etezadi-Amoli [18]. Love and Guo [64] summarised the general covariate structure as shown in Table 6: 


\begin{tabular}{|l|l|l|}
\hline Model & Hazard & Reliability \\
\hline PH & $\xi(z) h_{0}(t)$ & $\exp \left[-\xi(z) H_{0}(t)\right]$ \\
\hline AL & $\psi(z) h_{0}(\psi(z) t)$ & $\exp \left[-H_{0}(\psi(z) t)\right]$ \\
\hline SC & $h_{0}(\psi(z) t)$ & $\exp \left[-\frac{1}{\psi(z)} H_{0}(\psi(z) t)\right]$ \\
\hline Unified & $\xi(z) h_{0}(\psi(z) t)$ & $\exp \left[-\frac{\xi(z)}{\psi(z)} H_{0}(\psi(z) t)\right]$ \\
\hline
\end{tabular}

Table 6: A summary of covariate models

It is also worth emphasising contributions from the Lawless and Thiagarajah [58] CIF model development

$$
v\left(t ; H_{t}\right)=e^{\underline{\theta}^{\prime} \underline{z}(t)}
$$

where

$$
\underline{z}(t)=\left(z_{1}(t), \ldots, z_{p}(t)\right)
$$

is a vector of functions that may depend upon both system operating time $t$ and system operating/failure/repair (maintenance) history $H_{t}$ and $\underline{\theta}=\left(\theta_{1}, \ldots, \theta_{p}\right)$ ') is a vector of unknown parameters.

A unified CIF model reflects repair impacts to the system having Lawless and Thiagarajah's form [58]

$$
v\left(t ; H_{t}\right)=e^{\underline{\theta}^{\prime} \underline{z}(t)},
$$

can be developed, especially for a log-linear intensity function. For example, for intensity model

$$
\rho(t)=\exp (\alpha+\beta t)
$$


it can be formulated as

$$
\begin{aligned}
\underline{z}(t) & =\left(1, u(t), t_{N(t-)}\right), \\
\underline{\theta} & =(\alpha, \beta \lambda),
\end{aligned}
$$

and for the power law model

$$
\rho(t)=\alpha t^{\gamma}
$$

it can be formulated as

$$
\begin{aligned}
\underline{z}(t) & =(1, \log u(t), \log v(t)) \\
\underline{\theta} & =(\log \alpha, \beta \gamma)
\end{aligned}
$$

where

$$
s(t)=\frac{t}{u(t)}
$$

It is quite obvious for both models, $\beta=\gamma$ we have same-as-old case but if $\gamma=0$ we have a same-as-new case. If $\beta \neq \gamma$, for Cox and Lewis hazard model the CIF can be written as

$$
\left.v\left(t ; H_{t}\right)=\exp \mid(\gamma-\beta) t_{N(t-)}\right\rfloor \exp (\alpha+\beta t) .
$$

It can be seen that if $\beta>\gamma$ the term $\exp \left|(\gamma-\beta) t_{N(t-)}\right|<1$ thus each repair will decrease the intensity function and the process is improving. Similarly, $\beta=\gamma$ the system is neutral (minimum repaired). It can be also seen that if $\beta<\gamma$ the term $\exp \left\lfloor(\gamma-\beta) t_{N(t-)}\right\rfloor>1$ thus each repair will increase the intensity function and the process is damaged. For the power law intensity model the CIF can be expressed as 


$$
v\left(t ; H_{t}\right)=\left(\frac{t}{t-t_{N(t-)}}\right) \beta-\gamma \alpha t^{\gamma}
$$

Similarly, notice that $\left(\frac{t}{t-t_{N(t-)}}\right)>1$, if $\beta<\gamma$

the term $\left(\frac{t}{t-t_{N(t-)}}\right)^{\beta-\gamma}<1$ thus each repair will decrease the intensity function and the system is improved. Similarly, $\beta=\gamma$ the system is neutral (minimum repaired). It can be also seen that if $\beta>\gamma$ the term $\left(\frac{t}{t-t_{N(t-)}}\right)^{\beta-\gamma}>1$ thus each repair will increase the intensity function and the system is damaged.

Furthermore, because the system operating/environment setting may well affect system reliability and performance (statistical process control), the related covariate information should be a part of the system performance history $H_{t}$. In the CIF,

$$
\lambda\left(t ; H_{t}\right)=e^{\underline{\theta}^{\prime} \underline{z}(t)},
$$

where

$$
\underline{z}(t)=\left(1, u(t), t_{N(t-)}, z_{4}(t), \ldots, z_{p}(t)\right)
$$

and

$$
\underline{z}(t)=\left(1, \log u(t), \log v(t), z_{4}(t), \ldots, z_{p}(t)\right)
$$

are vectors of functions and

$$
\underline{\theta}=\left(\alpha, \beta, \gamma, \theta_{4}, \ldots, \theta_{p}\right)
$$

and

$$
\underline{\theta}=\left(\log \alpha, \beta, \gamma, \theta_{4}, \ldots, \theta_{p}\right)
$$


are vectors of parameters for Cox and Lewis and power law hazards respectively.

\section{SHOCK DAMAGE AND WEARING PROCESSES}

Another way to link the engineering information into a system's performance and survivability is shock damages and wears which are often observable or at least partially detectable in terms of sensor system and treated as accountable causes demanding maintenance attentions. The physical damage measure process

$\mathrm{X}=\left\{X_{t}, t \in \mathfrak{R}^{+}\right\}$is in nature a compounding process

$$
X_{t}=\alpha_{0}+\sum_{i=1}^{N_{t}} Y_{i}
$$

where $\left\{N_{t}, t \in \mathfrak{R}^{+}\right\}$is a counting process. A basic shock damage model assumes that a system has survived the first $k$ shocks, $k=0,1,2, \ldots$ with probability $\bar{P}_{k}$, where the shock numbers as the events occur in a Poisson process, the reliability is

$$
R(t)=\sum_{k=0}^{\infty} \overline{P_{k}} \frac{(\lambda t)^{k}}{k !} e^{-\lambda t}, \lambda>0 .
$$

Such models were investigated as early as by Esary from1950s and well investigated by Esary, Marshall and Proschan [27]. As a model to facilitate maintenance policy making during last decade can be referenced in the papers by Kijima and Nakagawa [50], Sheu and Liou [80], Feng, Adachi and Kowada [28] etc.

Hopp and Kuo [46] in their paper have a very detailed coverage on the cumulative shock model application to the maintenance of an aircraft engine compressor. They pointed out that the model usage is motivated by the fact that it facilitates a "good prediction of the times until failure of components", and "requires relatively few estimated parameters and therefore has relatively simple data requirements", and more importantly, "shocks can be defined so as to be easily monitored using modern aircraft sensors". The engineeringly observable (sensor) 
records and accordingly defined shock information provide the foundation for seeking mathematical model and related optimal maintenance policy.

The physical process descriptors were first identified and quantified: crack increments and shock occurrences. The crack increments, $Y_{i}$, is quantified by a distribution of Polya frequency of order 2 representing the crack growth and the variability in growth as well. Further the characterisation of the occurrence of shocks during a flight is a very balanced between engineering and mathematical consideration. It is assumed that a base rate $\lambda$ catches "the average number of times the stress on the components exceeds some threshold. ... because crack growth tends to accelerate with crack size, we must adjust this rate with a nonstationary function $s(\alpha, k)$ " with $\alpha$ representing crack size found at most recent inspection or replacement and $k$ being the number of shocks recorded since last inspection. With the notation of

$$
A(\alpha, k)=\alpha+\sum_{i=1}^{k} Y_{i}
$$

being the crack size found at inspection when the state is $(\alpha, k)$. The distribution of $\Delta k(\alpha, k)$, the number of shocks during a flight, is a Poisson $\left(\lambda_{s}(\alpha, k)\right)+1$ random variable. "Since the function $s(\alpha, k)$ offers more degree of freedom than we are likely to need, there will be considerable latitude in defining this function so as to fit the data." Let the critical crack size $\xi$ be a random variable so that if the crack size is larger than $\xi$ then a failure occurs. The probability of failure in flight when the state at the beginning of the flight is $s(\alpha, k)$ :

$$
p(\alpha, k)=\operatorname{Pr}\left[A(\alpha, k) \sum_{i=k+1}^{k+\Delta k(\alpha, k)} Y_{i}>\xi\right]
$$

Shock models in nature lead to the developments of compound (Poisson) processes, for example, Barbour, Chyssaphinou and Malgorzata [7]. 
For a repairable system, the time from which a defect can be identified at an inspection to the random time that the defect causes a system failure is said to be a delay time which was initiated by Christer and Wang [15], [16], and Christer, Wang, Baker and Sharp [17]. Just as Wang [90] pointed out "the delay time concept defines a two stage stochastic process where the first stage is the initiating phase of a defect, and the second is the stage where the defect leads to a failure." Assuming that the defects occurred and can be identified follow a point process $\left\{N_{t}, t \in \mathfrak{R}^{+}\right\}$, the $i^{\text {th }}$ delay time be $Y_{i}, i=0,1,2, \ldots$, and the interarrival time between the $i^{\text {th }}$ and $(i+1)^{s t}$ defects is $\left\{X_{t}, i=1,2, \ldots\right\}$, then the delay time

$$
Y_{N_{t}}=L-\sum_{i=1}^{N_{t}} X_{i}
$$

where $L$ is the lifetime starting as a defect-free system. Then the delay time is again a compound process similar to that of cumulative shock damage processes although the current treatments in the literature have not touched the compounding characteristic yet.

Scarf [75] pointed out a very simple two-parameter delay time model with Poisson process defect arrivals with rate $\alpha$; exponentially distributed delay-time with mean $\frac{1}{\gamma}$; perfect inspection with equal spaced inspections $\Delta)$. For a system observed over $(O, T)$, the equation

$$
\left\{\begin{array}{c}
\hat{\alpha} T=n \\
\frac{(n-k) \hat{\gamma} \Delta}{\exp (\hat{\gamma} \Delta)-1}+\frac{\sum \hat{\gamma} t_{j}}{\exp \left(\hat{\gamma} t_{j}\right)-1}=n-k
\end{array}\right.
$$

give the maximum likelihood estimates, where $k$ failures are observed at times $t_{i}(i=1,2, \ldots k)$ and $n-k$ defects are found at inspections.

Cerone [13] summarised that the modified form of delay time model for the reliability $R_{\Delta}(t)$ due to a periodic inspection every $\Delta$ time units

$$
R_{\Delta}(t)=r_{\Delta}^{(m)}(t),(m-1) \Delta \leq t \leq m \Delta
$$


where

$$
\begin{aligned}
& r_{\Delta}^{(m)}(t)=\sum_{j=1}^{m-1} k_{j}\left(\Delta r_{\Delta}{ }^{(m-1)}\right)(t-j \Delta)+B_{\Delta}(t) \\
& k_{j}(\Delta)=\int_{(j-1) \Delta}^{j \Delta} g(y) M(j \Delta-y) d y \\
& B_{\Delta}(t)=\int_{t}^{\infty} g(y) d y+\int_{(m-1) \Delta}^{t} g(y) M(t-y) d y \\
& M(x)=\int_{t}^{\infty} f(u) d u=1-F(x)=S(x)
\end{aligned}
$$

He further developed the converse problem in terms of delay time model. In its simplest form, given the number of inspections, the determination of the inspection interval $\Delta$ will result in the maximum reliability at some future point in time $t=t^{*}$. In other words, the converse problem to be addressed here is to find the optimal inspection interval $\Delta_{\max }$, given a desired numbers of inspection m-1. It is assumed that the system is inspected at periodic interval of length $\Delta$ and the system is replaced or repaired same-as-new if the system is found to be $\Delta_{\max }$ defect. The optimal inspection interval length $\Delta$ need to satisfy the following equation by specifying $t=t^{*}$

$$
r_{\Delta}^{(m)}\left(t^{*}\right)=\sum_{j=1}^{m-1} k_{j}(\Delta) r_{\Delta}^{(m-1)}(t-j \Delta)+B_{\Delta}\left(t^{*}\right), \frac{t^{*}}{m} \leq \Delta \leq \frac{t^{*}}{m-1}
$$

where $k_{j}(\Delta)$ and $B_{\Delta}\left(t^{*}\right)$ are defined as above.

A wearing (deterioration) process modelling of repairable system example worth to mention is the work of Van Noortwijk, Cooke and Kok [68]. Although their interest was developing a new failure model for hydraulic structures, the spirit of the research pointed out how to develop a repairable system modelling by utilizing the engineering based information. The 
"model is based on amounts of deterioration appearing per unit time; on quantities that can be observed, or about which engineers are able to have a subjective opinion." The developments were based on the fact that "a lack of deterioration data is common at the outset" in the field of hydraulic engineering and "most maintenance decisions are only based on ideas about average wearout".

By assuming a $l_{1}$-isotropic stochastic deterioration process, Van Noortwijk et. al. [68] developed the probability of failure without inspection, the probability of failure with inspection and the probability of preventive repair distribution under Bayesian decision theory for the rock-fill top-layer of the bed protection of the Eastern Scheldt Storm-Surge Barrier. Their results clearly indicated that the repairs do change the failure behaviour of the wearing deterioration process.

It is also worth to mention as a final comment in this section that compound processes have been gained substantial attention in financial modelling and a rich literature is expanding there. Reliability engineers and researchers should widen their mind and learn the modelling experience from financial research for a better modelling practice in repairable systems.

\section{CONCLUDING REMARKS}

In this paper, we have tried to cover the generalised models in repairable system modelling, particularly concentrating on "hot" spots as well as practical models except for the multicomponent repairable system modelling in the last five years. The manner in which we reviewed those models is not exhaustive but tries to examine their underlying physical and engineering mechanism, i.e., the stochastic processes behind those general models, because operating / failure / maintenance processes are in nature stochastic processes. It is not as an advertising campaign that we listed our works before 1995, rather it is to emphasise our criticisms and suggestions in repairable system modelling are based on our own background and experience.

The reason we emphasise the view of practical models rather the simple models is two folds: firstly, engineers and managers need those models able to reflect their process information or data; secondly, theory of stochastic processes is not often readily available to engineers and managers. We review those models and their underlying stochastic processes in an 
interpretative and informal manner, unconstrained by rigorous mathematical development. The intrinsic age process with a Markov renewal process foundation may provide an extremely simple form linking to hazard and accumulative hazard concepts and thus will be an useful frame for a wide range of repairable system modelling. The physical role of intrinsic age is different from virtual age (similar to a bioclock in human body) which is more global. Intrinsic age is a more local concept and it may better illustrate instantaneous failure behaviour. On the other hand, virtual age is invisible but does function within every system. Virtual age models enjoyed a great popularity with researchers but the model structures imposed for virtual age may cause some problems as we pointed out earlier in this paper. In a certain sense, the introduction of marked point process as underlying stochastic process is a milestone in virtual age modelling. Particularly, the marked point process approach may be reasonably justify all the statistical inference issues, say, estimation, stability of the estimation etc. The condition monitoring technique related models for repairable systems are an excellent hybrid of mathematical theory and engineering information. Currently, as a part of system design, a lot of system sensors and self-checking mechanism are built-in. But the information is often ignored during repairable system modelling. Practical experience of using proportional hazards (intensities), accelerating life models and possible more general modelling structure not only won the heart of engineers and managers but also promoted more interest of theoretical research. Some criticism mentioned in Scarf [75] suggested that as a practical means, some engineering intuitiveness can always help to overcome those difficulties. For example, a properly combined virtual age model and proportional intensity mixture may lead to more efficiency in modelling, just as Guo and Love [41] and [42] demonstrated in their simulation paper demonstrated. The cumulative damage and wearing processes and their close cousins, delay-time related processes, are in nature compounding stochastic processes. Some aspects of them were fully explored but the delay-time related compound processes are worth further effort. Some progress has been made in the statistical estimation aspect, for example, Costantini and Spizzichino [19], Gasmyr [34], Guo and Love [43], Silver and Fiechter [81], Tang, Tang and Moskwitz [87], and Xie and Lai [94].

It is reasonable to say that the two extreme cases: same-as-new and same-as-old are mostly explored because of mathematical simplicity. However, those two extremes are often not realistic. One of the reasons why they were popular was because they well reflected the yes or no classic Cantor set theory logic. Practice cannot rule out the states evolving between the 
perfect repair and the minimum one, therefore the fuzzy concept can be introduced to reflect such reality, although some further mathematical complexity has to be induced.

The last point we would like to raise is that all the above mentioned stochastic processes models for repairable systems are under the 'standing alone' environment. We use the term, standing alone, to indicate that the system environment does not involve where the systems are and what are the systems are installed for. Actually reliability is a part of the total quality measures of product or service, while the quality issue itself is subject to the total business environment. Over-emphasising the optimisation of the reliability index and cost is questionable in practice. Researchers in recent years have begun to realise that the current outlook of reliability modelling may lead nowhere. For example, Sonin [83] reveals that increasing the reliability of a machine reduces the period of its work. Therefore, a holistic view on reliability and quality improvement research should put repairable system modelling under the overall business and production environments and the interested reader can reference the work by Ushakov and Harrison [88], Goyal, Gunasekraan, Yli-olli [37], Gob, Beichelt, Drager, Ramalhoto and Schneideman [35], Wang, Gary and Scott [91] and Diederid, Jan and Hontelez [92].

\section{REFERENCES}

[1] H.E. ASCHER and FEINGOLD, Repairable System Reliability: Modelling, Inference, Misconceptions and Their Causes, Dekker, New York (1984).

[2] H.E. ASCHER, Basic probabilistic and statistical concepts for maintenance of parts and systems, IMA Journal of Mathematics Applied in Business \& Industry, 3, 153-167, Oxford University Press (1992).

[3] H.E. ASCHER and K.A.H. KOBBACY, Modelling preventive maintenance for deteriorating repairable system, IMA Journal of Mathematics Applied in Business \& Industry, 6, 85-99, Oxford University Press (1995).

[4] H.E. ASCHER and CHRISTIAN K. HANSEN, Spurious Exponentiality Observed when Incorrectly Fitting a Distribution to Nonstationary Data, IEEE Transaction on Reliability, 47, No.4, 451-459 (1998).

[5] H.E. ASCHER, A Set-of-Number is Not a Data-Set, IEEE Transaction on Reliability, 48, No. 2, 135-140 (1999). 
[6] H. E. ASCHER and CHRISTIAN K. HANSEN, Comment on: Stupid statistics (Editorial) IEEE Transaction on Reliability, 49, No. 2, 134-135 (2000).

[7] A. D. BARBOUR, OURANIA CHRYSSAPHINOU and MALGORZATA ROOS, Compound Poisson approximation in system reliability, Naval Research Logistics, 43, 251-264 (1996).

[8] R.E. BARLOW and L. C. HUNTER, Optimum preventive maintenance policies, Operations Research, 8, 90-100 (1960).

[9] L. A. BAXTER, M. KIJIMA and M. TORTORELLA, A Point Process Model for the Reliability of a Maintained System Subject to General Repair, Communications in Statistics-Stochatistic Models, 1, 37-65 (1996).

[10] J. BERTOIN, Levy Processes, Cambridge University Press, Cambridge, (1996).

[11] PHILLIP J. BOLAND and EMAD EL-NEWEIHI, Statistical and information based (physical) minimal repair for k out of n systems, Journal of Applied Probability, 35, 731-740 (1998).

[12] F. A. BOSHUIZEN, Optimal replacement strategies for repairable systems, Zeitschrift fur Operations Research, 45, No. 1), 133-144 (1997).

[13] P. CERONE, Inspection interval for maximum future reliability using the delay time model, European Journal of Operational Research, 68, 236-250 (1993).

[14] MINGCHIH CHEN and RICHARD M. FELDMAN, Optimal replacement policies with minimal repair and age-dependent costs, European Journal of Operational Research, 98, 75-84 (1997).

[15] A.H. CHRISTER and W. WANG, A delay-time based maintenance model of a multicomponent system, I.M.A. Journal of Mathematics Applied in Business and Industry, 6, 205-236 (1995a).

[16] A.H. CHRISTER and W. WANG, A simple condition monitoring model for a direct monitoring process, European Journal of Operational Research, 82, 258-269 (1995b).

[17] A.H. CHRISTER, W. WANG, R.D. BAKER and J.SHARP, Modelling maintenance practice of production plant using the delay-time model, M.A. Journal of Mathematics Applied in Business and Industry, 6, 67-84 (1995).

[18] A. CIAMPI and J. ETEZADI-AMOLI, A General Model for Testing the Proportional Hazards and the Accelerated Failure Time Hypothesis in The Analysis of Censored Survival Data with Covariates. Communication in Statistics-Theory and Methods, 14, No. 3, 651-667 (1985).

[19] C. COSTANTINI and E. SPIZZICHINO, Explicit solutions of an optimal stopping problem: The burn-in of conditional exponential components, Journal of Applied Probability, 34, 267-282 (1997). 
[20] D.R. COX, Regression Models and Life Tables (with discussion). Journal of the Royal Statistical Society, B 34, 187-220 (1972).

[21] J.S. DAGPUNAR, Some properties and computational results for a general repair process, Naval Research Logistics, 45, 391-405 (1998).

[22] C.J. DALE, Application of Proportional Hazard Model in the Reliability Field, Reliability Engineering, 10, 1-14 (1985).

[23] R. DEKKER, Integrating optimization, priority setting, planning and combining of maintenance activities, European Journal of Operational Research, 82, 225-240 (1995).

[24] R. DEKKER, Applications of maintenance optimization models: a review and analysis. Reliability Engineering and System Safety, 51, 229-240 (1996).

[25] K. DEVARAJAN and N. EBRAHIMI, A nonparametric approach to accelerated life testing under multiple stresses, Naval Research Logistics, 45, 629-644 (1998).

[26] RAN EL-YANIV and RICHARD M. KARP, Nearly optimal competitive online replacement policies, Mathematics of Operations Research, 22. No. 4. 814-839 (1997).

[27] J. D. ESARY, A. W. MARSHALL and F. PROSCHAN, Shock Models and Wear Processes, The Annals of Probability, 1, No. 4, 627-649 (1973).

[28] W. FENG, K. ADACHI and M. KOWADA, An optimal state-age dependent replacement for a network system, European Journal of Operational Research, 75, 634-646 (1994).

[29] M.S. FINKELSTEIN, On Some Models of General Repair, Microelectronics and Reliability, 33, No. 5, 636-666 (1993).

[30] M.S. FINKELSTEIN, A point process stochastic model with application to safety at sea, Reliability Engineering and System Safety, 60, 227-233 (1998).

[31] M.S. FINKELSTEIN, Multiple availability on stochastic demand, IEEE Transactions on Reliability, 48, 19-25 (1999).

[32] M.S. FINKELSTEIN, On Some Approaches to Hazard Rate Modelling, South African Statistical Journal, 34, No. 2, 93-109 (2000).

[33] STEVEN T. GARREN and DONALD P. RICHARD, General conditions for comparing the reliability functions of systems components sharing a common environment, Journal of Applied Probability, 33, 124-135 (1998). 
[34] J. GASMYR, On identifiability in the autopsy model of reliability system of lifemonitored and conditionally lifemonitored components, Journal of Applied Probability, 35, 427-437 (1998).

[35] RAINER GOB, FRANK BEICHELT, KLAUS DRAGER, MARIA FERNANDA RAMALHOTO and HERBERT SCHNEIDEMAN, Process maintenance from the point of view of reliability theory and of statistical process control (1994).

[36] LINGUO GONG, JAMES PRUETT and KWEI TANG, A Markovian model for process setup and improvement, Naval Research Logistics, 44, 383-410 (1997).

[37] S.K. GOYAL, A. GUNASEKARAN and P. YLI-OLLI, Integrating production and quality control policies: A survey, European Journal of Operational Research, 69, 113 (1993).

[38] JOSE M. GOUWELEEUW, A minimax optimal stop rule in reliability checking, Journal of Applied Probability, 35, 748-761 (1998).

[39] R. GUO and C.E. LOVE, Statistical Analysis of an Age Model for Imperfectly Repaired Systems, Quality and Reliability Engineering International, 8, 132-146 (1992).

[40] R. GUO and E. A. BRADLEY, Statistical Analysis of Repairable System with General Repair, Proceedings of the 2nd Asian Congress on Quality and Reliability\}, May 31June 3, Beijing, China (1993).

[41] R. GUO and C.E. LOVE, Simulating Nonhomogeneous Poisson Processes with Proportional Intensities, Naval Research Logistics, 41, 507-522 (1994).

[42] R. GUO and C.E. LOVE, Bad-As-Old Modelling of Complex Systems with Imperfectly Repaired Subsystems, Proceedings of the International Conference on Statistical Methods and Statistical Computing for Quality and Productivity Improvement, August 17-19, Seoul, Korea, 131-140 (1995).

[43] R. GUO and C. E. LOVE, Linear-Spline Approximation for Semi-Parametric Modelling of Failure Data with Proportional Hazards, IEEE Transaction on Reliability, 45, No. 2, 261-266 (1996).

[44] R. GUO and L. FRERICHS, Time and Financial risk, paper presented in the 27th Meeting of Euro Working Group on Financial Modelling, New York, November 1820 (2000).

[45] A. HAURIE, Time scale decomposition in production planning for unreliable flexible manufacturing systems, European Journal of Operational Research, 82, 329-358 (1995).

[46] WALLACE J. HOPP and YAR-LIN KUO, An optimal structured policy for maintenance of partially observable aircraft engine components, Naval Research Logistics, 45, 335-352 (1998). 
[47] A.K.S. JARDINE, P.M. ANDERSON, and D.S. MANN, Application of the Weibull Proportional Hazards Model to Aircraft and Marine Engine Failure Data, Quality and Reliability Engineering International, 3, 77-82 (1987).

[48] X. JIANG, K. CHENG and V. MARKIS, On the optimality of repair-cost-limit policies, Journal of Applied Probability, 35, 936-949 (1998).

[49] M. KIJIMA, Some results for repairable systems with general repair, Journal of Applied Probability, 26, 89-102 (1989).

[50] M. KIJIMA and K. NAKAGAWA, Accumulative damage shock model with imperfect preventive maintenance, Naval Research Logistics, 145-156 (1991).

[51] M. KIJIMA, Hazard rate and reversed hazard rate monotoncities in continuous-time Markov Chains, Journal of Applied Probability, 35, 545-556 (1998).

[52] D. KUMAR and B. KLEFSJ, Proportional Hazards Model: A Review Reliability Engineering and System Safety, 44, 177-188 (1994).

[53] D. KUMAR, Proportional Hazards Modelling of Repairable Systems, Quality and Reliability Engineering International, 11, 361-369 (1995).

[54] D. KUMAR and U. WESTBERG, Maintenance scheduling under age replacement policy using proportional hazards model and TTT-plotting, European Journal of Operational Research, 99, 493-506 (1997).

[55] GUNTER LAST and ANDREAS BRANDT, Marked Point Processes on the Real Line: the Dynamic Approach, Springer (1995).

[56] GUNTER LAST and RYSZARD SZEKLI, Stochastic comparison of repairable systems by coupling, Journal of Applied Probability, 35, 348-370 (1998).

[57] J.F. LAWLESS, Statistical Models and Methods for Lifetime Data, Wiley, New York (1983).

[58] J. E. LAWLESS and K. THIAGARAJAH, A point-process model incorporating renewal and time trend, with application to repairable systems. Technometrics, $\mathbf{3 8}$, 131-138 (1996).

[59] HAIJUN LI, MOSHE SHAKED, Aging first-passage times of a Markov processes: A matrix approach, Journal of Applied Probability, 34, 1-34 (1997).

[60] WEI LI, DINGHUA SHI and XIU LI CHAO, Reliability analysis of M/G/1 queuing systems with server breakdowns and vacations, Journal of Applied Probability, 34, 546-555 (1997).

[61] C.E. LOVE and R. GUO, Using Proportional Gazard Modelling in Plant Maintenance, Quality and Reliability Engineering International, 7, 7-17 (1991). 
[62] C.E. LOVE and R. GUO, Application of Weibull Proportional Hazards Modelling to Bad-As-Old Failure Data, Quality and Reliability Engineering International, 7, 149157 (1991).

[63] C.E. LOVE and R. GUO, Simulation Strategies to Identify the Failure Parameters of Repairable Systems under the Influence of General Repair, Quality and Reliability Engineering International, 10, 37-47 (1994).

[64] C.E. LOVE and R. GUO, Statistical Analysis of General Covariate Structure, Proceedings of the International Conference on Statistical Methods and Statistical Computing for Quality and Productivity Improvement, August 17-19, Seoul, Korea, 131-140 (1995).

[65] C.E. LOVE and R. GUO, Utilizing Weibull Failure Rates in Repair Limit Analysis for Equipment/Preventive Maintenance Decisions, Journal of the Operational Research Society, 47, 1366-1376 (1996).

[66] C.E. LOVE, Z.G. ZHANG, M.A. ZITRON and R. GUO, A discrete Semi-Markov Decision Model to Determine the Optimal Repair /Replacement Policy under General Repairs, European Journal of Operational Research, 125, 398-409 (2000).

[67] VILIAN MAKIS and ANDREW K.S. JARDINE, A note on optimal replacement policy under general repair, European Journal of Operational Research, 69, 75-82 (1993).

[68] JAN M. VAN NOORTWIJK, ROGER M. COOKE and MATTIJS KOK, A Bayesian failure model based on isotropic deterioration, European Journal of Operational Research, 82, 270-282 (1995).

[69] SULEYMAN OZEKICI, Optimal maintenance policies in random environments, European Journal of Operational Research, 82, 283-294 (1995).

[70] D.F. PERCY, K.A.H. KOBBACY, and H.E. ASCHER, Using proportional-intensities models to schedule preventive-maintenance intervals, IMA Journal of Mathematics Applied in Business \& Industry, 9, 289-302, Oxford University Press (1998).

[71] HOANG PHAM and HONGZHUO WANG, Imperfect maintenance, European Journal of Operational Research, 94, 425-4384 (1996).

[72] L.M.A. PINTELON, F.L.B. VAN PUYVELDE and L.F. GELDERS, An age-based replacement policy with non-zero repair times for a continuous production process, International Journal of Production Research, 33, No. 8, 2111-2123 (1995).

[73] B.L.S. PRAKASA RAO, Semimartingales and their Statistical Inference, Chapman \& Hall CRC (1999).

[74] RHONDA RIGHTER, Optimal policies for Scheduling repairs and allocating heterogeneous servers, Journal of Applied Probability, 33, 536-547 (1996) 
[75] PHILLIP A. SCARF, On the application of mathematical models in maintenance, European Journal of Operational Research, 99, 493-506 (1997).

[76] S.H. SHEU, A generalized model for determining optimal number of minimal repairs before replacement, European Journal of Operational Research, 69, 38-49 (1993).

[77] SHEY-HUEI SHEU, Extended block replacement policy with used item and general random minimal repair cost, European Journal of Operational Research, 75, 647-658 (1994).

[78] SHEY-HUEI SHEU, A modified block replacement policy with two variables and general random minimal repair cost, Journal of Applied Probability, 33, 546-555 (1996)

[79] SHEY-HUEI SHEU and JHY PING JHANG, A generalized group maintenance policy, European Journal of Operational Research, 96, 232-247 (1996).

[80] SHEY-HUEI SHEU and C.T. LIOU, Optimal replacement of a k-out-of-n system subject shocks, Microelectronics and Reliability, 649-655 (1992).

[81] EDWARD A. SILVER and CLAUDE -NICOLAS FIECHTER, Preventive maintenance with limited historical data, European Journal of Operational Research, 82, 125-144 (1995).

[82] HARSHINDER SINGH and RADHEY SINGH, Note: Optimal allocation of resources to nodes of series systems with respect to failure-rate ordering, Naval Research Logistics, 44, 147-152 (1997).

[83] ISAAC M. SONIN, Increasing the reliability of a machine reduces the period of its work, Journal of Applied Probability, 33, 217-223 (1996).

[84] WOLFGANG STADJE and DROR ZUCKERMAN, Optimal Maintenance Strategies for Repairable Systems with General degree of Repair, Journal of Applied Probability, 28, 384-396 (1991).

[85] W WOLFGANG STADJE and DROR ZUCKERMAN, A generalized maintenance model for stochastically deteriorating equipment, European Journal of Operational Research, 89, 285-301 (1996).

[86] TADASHI, NOBUYUKI MATSUSHIMA, NAOTA KAIO and SHUBJI OSAKI, Nonparametric repair-limit replacement policies with imperfect repair, European Journal of Operational Research, 96, 260-273 (1996).

[87] JEN TANG, KWEI TANG, and HERBERT MOSKWITZ, Exact Bayesian estimation of system reliability from component data, Naval Research Logistics, 44, 127-146 (1996). 
[88] IGOR A. USHAKOV and ROBERT A. HARRISON, Handbook of Reliability Engineering, John Willey \& Sons, Inc. New York (1994).

[89] F.A. VAN DER DUYN SCHOUTEN and S.G. VANNESTE, Maintenance optimization of a production with buffer capacity, European Journal of Operational Research, 82, 323-338 (1995).

[90] W. WANG, Subjective estimation of the delay time distribution in maintenance modelling, European Journal of Operational Research, 99, 516-529 (1997).

[91] P.P. WANG, W. GARY, and M. SCOTT, Quality-related measures of unreliable machines with preventative maintenance, Computers and Operations Research, 10, 981-996 (1996).

[92] J. D. DIEDERID, WIJNMALEN JAN and A.M. HONTELEZ, Coordinated condition-based repair strategies for components of a multi-component maintenance system with discounts, European Journal of Operational Research, 98, 52-63 (1997).

[93] L. R. WHITAKER and F. J. SAMANIEGO, Estimating the reliability of systems subject to imperfect repair, American Statistical Association, 84, 405, 301-309 (1989).

[94] M. XIE and C.D. LAI, On reliability bounds via conditional inequalities, Journal of Applied Probability, 35, 104-114 (1998).

[95] V.M. ZOLOTAREV, One-dimensional Stable Distributions. (Translations of mathematical Monographs Vol 65), American Mathematical Society (1986). 